\section{SUJETOS EN EMERGENCIA: ACCIONES COLECTIVAS DE RESISTENCIA Y ENFRENTAMIENTO DEL RIESGO ANTE DESASTRES; EL CASO DE CHAITÉN, CHILE'}

\author{
Ana María Ugarte 2 , Marcela Salgado 3
}

\section{Resumen}

Los desastres socionaturales, al irrumpir en un territorio, dejan en evidencia diferentes vulnerabilidades y riesgos presentes en las poblaciones afectadas; por ende el manejo que se haga de estas situaciones, a nivel de política pública, impacta directamente en la percepción de riesgo y en la significación misma de la vivencia por parte de quienes la experimentan. El 2 de mayo de 2008 Chile vivió la erupción del volcán Chaitén, ubicado en la ciudad de Chaitén, Región de Los Lagos. La erupción del volcán y el desborde de un río de la zona destruyeron la ciudad, y las acciones públicas para la evacuación y posterior retorno de la población

\section{EMERGENT SUBJECTS: COLLECTIVE ACTS OF RESISTANCE AND RISK CONFRONTATION IN THE FACE OF DISASTERS; THE CASE OF CHAITÉN, CHILE'}

Ana MaríaUgarte ${ }^{2}$, Marcela Salgado 3

\section{Abstract}

Socionatural disasters reveal the different vulnerabilities and risks of stricken areas; this is why the control of these situations at public policy level has a direct impact on the perception of risk and the significance of the experience of affected people. On May 2, 2008, Chile experienced the eruption of Chaitén volcano, located in the city of Chaitén, Los Lagos Region. The volcanoeruption and the overflow of a river destroyed the city and public actions for the evacuation and subsequent return of local people disrupted social systems and daily relationships at public and private level. This generatedcollapses within work and family structures 
desarticularon, tanto en lo público como en lo privado, los sistemas sociales y vínculos cotidianos, generando rupturas en las estructuras de trabajo y familiares y cambios de las relaciones del Estado con los ciudadanos. En este marco, a través de estrategias cualitativas, se analiza el caso de Chaitén, haciendo énfasis en la vivencia y significación del desastre, en el impacto a nivel de identidad territorial, en la evaluación de las políticas públicas, y en las acciones colectivas de enfrentamiento del riesgo generadas por sus habitantes.

\section{PALABRAS CLAVES: POLÍTICA PÚBLICA, DESASTRE SOCIONATURAL, IDENTIDAD TERRITORIAL, ACCIÓN COLECTIVA.}

Fecha de recepción: 25.06.2013

Fecha de aceptación: 17.01.2014

1 Proyecto Centro de Investigación en Vulnerabilidades y Desastres Socionaturales (CIVDES), $N^{\circ} 100022$

2 Chile. Psicóloga, estudiante de Magíster en Ciencias Sociales, Universidad de Chile. Docente del Departamento de Psicología, Universidad Católica Silva Henríquez. Correo electrónico: amuc@u.uchile.cl

3 Chile. Socióloga, Magíster en Gestión y Planificación Ambiental Universidad de Chile. Correo electrónico: salgado.marcela@ gmail.com

144 revista invi № 80 / May 2014 / Volume N² 29: 143-168 and changes in the relationship between the State and citizens. Through the use of qualitative strategies, the paper analyzes the Chaitén case by focusing on the experience and significance of such a disaster on the impact at territorial identity level, including the evaluation of public policies and the collective actions of risk confrontation generated by the inhabitants themselves.

\section{KEYWORDS: PUBLIC POLICY, SOCIONATURAL DISASTER, TERRITORIAL IDENTITY, COLLECTIVE ACTION}

Received: 25.06.2013

Accepted: 17.01.2014

1 Research Center on Vulnerability and Disasters (CIVDES) project $\mathrm{N}^{\circ} 100022$

2 Chile, Psychologist, Master's student in Social Sciences, University of Chile. Professor, Department of Psychology, Silva Henríquez Catholic University.Email: amuc@u.uchile.cl

3 Chile. Sociologist, MA in Environmental Management and Planning, University of Chile. Email: salgado.marcela@gmail.com 


\section{Introducción}

Los desastres socionaturales provocan múltiples transformaciones en la esfera de las relaciones Estado-Sociedad. Lo que parece estar en conflicto allí es la democracia y sus límites, y la capacidad del Estado y sus obligaciones ${ }^{4}$. Como figura, el Estado tiene un carácter polifacético, lo que implica que este no es sólo una entidad social compleja compuesta por distintos elementos; sino que además existe en diversos planos de la realidad social. Así, puede entenderse al Estado como forma de representación colectiva de la sociedad, en cuanto medio para la realización del interés general que requiere de instituciones para hacerse concreta y expresar los intereses de la sociedad ${ }^{5}$.

También puede conceptualizarse al Estado como forma de dominación, como aparato que se organiza para el control social en forma regular y continua, como una forma de generar y utilizar activa y pasivamente el poder ${ }^{6}$. Una tercera forma de entender al Estado es teorizarlo como institución social, donde espercibido como la regulación de la esfera pública: sería el que delimita los espacios regulados y desregulados para la realización concreta de los intereses privados y de los intereses públicos ${ }^{7}$.

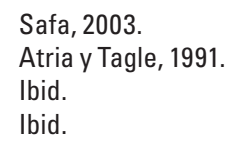

Asimismo, el Estado puede ser comprendido como actor social, como gestor de iniciativas, como sujeto de políticas que actúa en distintos niveles: (1) A un nivel primario, donde regula los eventos vitales de las personas o de los grupos, o de los intercambios elementales que se dan entre los individuos dentro de la sociedad, como el intercambio de bienes y servicios; (2) A un nivel compensatorio, generando políticas que buscan corregir las distribuciones de bienes, servicios y oportunidades resultantes de las estructuras económicas y sociales; (3) Y a un nivel de politicas terciarias o estructurales, por las cuales busca afectar las distribuciones sociales y económicas tratando de apuntar a las causas que originan el hecho de que ciertos grupos detenten mayor poder que otros ${ }^{8}$.

Esta última representación se relaciona directamente con el ejercicio de políticas públicas. Cuando estas no son efectivas o son disonantes con los intereses de la sociedad de base, surgen actores que buscan hacer sentir su presencia en términos de influencia y capacidad de veto político ${ }^{9}$. Autores como Lahera ${ }^{10}$ proponen que las políticas públicas tienen una función eminentemente política, por ello, aun cuando se debe buscar una mayor capacidad de gestión pública estratégica esta no debe apuntar a despolitizar la política, sustituyéndola

$\begin{array}{ll}8 & \text { Ibid. } \\ 9 & \text { Lahera, } 2006 . \\ 10 & \text { lbid. }\end{array}$


por decisiones técnicamente óptimas respecto a la asignación o utilización de los recursos, que no consideren los diversos conflictos de intereses, contextos sociales y distintas visiones que existen en un territorio. Según Charlin ${ }^{11}$, lo político en las políticas públicas debe incluir siempre la participación ciudadana; lo cual, según el autor, implicaría mayor compromiso de parte de los ciudadanos con la creación y ejecución de las políticas públicas, así como con su supervisión, pues las decisiones tomadas estarían basadas en su participación y además, en una racionalidad más amplia que la puramente técnica, incluyendo los saberes y experiencias aportadas por los ciudadanos.

Todo lo señalado anteriormente se pone en juego cuando un Estado enfrenta eventos catastróficos como un desastre socionatural, particularmente se tensa la capacidad del Estado para dar respuesta a las demandas ciudadanas a través de políticas públicas participativas. De hecho, las recientes experiencias de desastres socionaturales que han tenido lugar en gran parte de Latinoamérica, han dejado en evidencia, por una parte, distintas situaciones de vulnerabilidad de nuestras poblaciones ante eventos como estos, y por otra, la falta de organización, coordinación y experiencia de la política pública para afrontar este tipo de emergencias ${ }^{12}$.

11 Charlin, 2007.

12 Vargas, 2002.
Ante este panorama, surgen acciones locales de enfrentamiento del riesgo, principalmente gestionadas desde la ciudadanía, entendida esta como el estatus que permite a los sujetos ejercer un conjunto de derechos y deberes cívicos, políticos y sociales ${ }^{13}$.

En Chile se vivió una experiencia particular de desastre socionatural que resulta altamente interesante de analizar respecto de la percepción que tienen los ciudadanos acerca de la acción del Estado a nivel de política pública social y de las acciones que estos mismos emprenden para enfrentar el riesgo. El 2 de mayo de 2008 hace erupción el volcán Chaitén, ubicado en la ciudad de Chaitén, Región de Los Lagos, lo que trajo como una de sus múltiples consecuencias, la inundación del sector por el desborde del río Blanco, a causa de la saturación de su cauce por las cenizas; lo que implicó que la ciudad se dividiera en dos, ya que al desbordarse el río atravesó la zona de oriente a poniente, formando un nuevo cause que dejó a Chaitén divido en dos espacios geográficos: el norte y el sur.

Ante esta situación, la acción estatal involucró diversos mecanismos para enfrentar la emergencia de Chaitén. En un primer momento, el de la emergen$\mathrm{cia}^{14}$, fue el gobierno central, a través de una Delegación Presidencial especialmente designada para este

13 Borja en Safa, 2003, p.3.

14 Periodo de tiempo contemplado entre la erupción del volcán y los primeros tres meses posteriores a esta (Marchant, 2010). 
caso, quien se hace cargo de responder ante el desastre, coordinándose con la ONEMI ${ }^{15}$ y los distintos ministerios. Estas autoridades deciden evacuar por completo la ciudad, trasladando a un total de 4.700 personas en 24 horas desde Chaitén hacia distintos destinos principalmente ubicados en el sur del país, como Puerto Montt, Chiloé y Futaleufú, entre otros ${ }^{16}$, ubicando a las personas en albergues temporales (durante 2 meses), dándoles un bono por la emergencia y apoyo en alimentación y vestuario.

Posteriormente, cuando el gobierno declara la ciudad de Chaitén como inhabitable por ser alto el riesgo de un nuevo desastre natural, este comienza a generar acciones de apoyo a quienes quedan en calidad de desplazados, las que consisten principalmente en bonos de manutención y un subsidio para la vivienda ${ }^{17}$, junto con la oferta de compra de las casas de los chaiteninos, al mismo precio avaluado antes del desastre ${ }^{18}$ y con la oferta de apoyo psicosocial (atención psicológica y capaci-

15 Oficina Nacional de Emergencias de Chile.

16 ONEMI, 2008a y b; Arias en Marchant, 2010.

17 Marchant, 2010.

18 Chile, Ministerio de Bienes Nacionales, 2009. tación laboral). Durante este periodo, el gobierno anuncia la creación de una nueva ciudad para los chaiteninos, el Proyecto Santa Bárbara ${ }^{19}$; sin embargo, esta nunca se concreta y en abril de 2010 la nueva administración ${ }^{20}$ anuncia oficialmente que las personas pueden retornar al sector norte de Chaitén ${ }^{21}$.

Tras esta declaración de habitabilidad de Chaitén y posibilidad de retorno para la población desplazada, el gobierno central comienza a retirarse de escena y aparece fuertemente el gobierno local (Gobernación Regional y Servicios Municipales) en el periodo de retorno y reconstrucción. De este modo, el gobierno central provee a sus habitantes de algunas estructuras de oportunidades y servicios básicos, como educación y salud, que permiten el retorno de algunas personas; sin embargo, no otorga una oferta concreta de reconstrucción del territorio. El gobierno local, por su parte, lleva a cabo acciones que consisten básicamente en

19 Este proyecto, ideado por las anteriores autoridades del Ministerio de Vivienda y Urbanismo de Chile, se erigía como una idea de ciudad modelo para 5.000 habitantes, segura, ambiental y económicamente sustentable; a sólo $10 \mathrm{~km}$ de Chaitén. Sin embargo, por el alto costo de inversión, estimado en unos US $\$ 300$ millones, el proyecto fue desechado por la actual Administración (Neira, 2010).

20 El abordaje de la problemática de Chaitén entre 2008 e inicios de 2010 se realiza en la Administración de Michelle Bachelet; luego, quien continúa el trabajo es la Administración del actual presidente Sebastián Piñera, quien asume el gobierno del país en marzo de 2010.

21 Marchant, 2010. 
administrar viviendas para el retorno; otorgar orientación a la comunidad, proveer servicios básicos (luz, agua, alcantarillado), otorgar acceso a la escuela (bus de acercamiento), y reparar algunas casas de los daños ocasionados por las cenizas.

A partir de lo anteriormente expuesto, se puede decir que la erupción volcánica destruyó estructuralmente la ciudad, desarticulando, tanto en lo público como en lo privado, los distintos sistemas sociales y vínculos cotidianos establecidos entre las personas y comunidades que convivían en los territorios afectados, generando rupturas en las estructuras de trabajo, en las familias y grandes cambios de relaciones dentro de las comunidades ${ }^{22}$, evidenciando diferentes vulnerabilidades sociales y nuevos riesgos. Además de lo señalado, el impacto del desastre se manifiesta, al mismo tiempo, en la relación que establece la comunidad con el territorio; impactos que, en función de las distintas etapas del desastre, se traducen en sentimientos de desarraigo e incertidumbre. Por otra parte, las transformaciones territoriales, como la división entre Chaitén norte y Chaitén sur, se convierten en elementos centrales en los procesos actuales de construcción de identidad colectiva, dando paso a procesos de significación inter-subjetiva entre los habitantes del nuevo territorio. Todo este proceso se materializa en acciones de resistencia y lucha por el control del territorio, que muestra a los chaiteninos que han retornado como protagonistas de su propia historia, en un proceso de toma de conciencia respecto de sus posiciones estructurales, de interactuar con otros en la construcción de proyectos colectivos, con espíritu crítico y capacidad de autorreflexión.

Considerando todo este contexto, resulta altamente interesante identificar y comprender las transformaciones en las relaciones entre el Estado y la ciudadanía a causa de este desastre que tienen lugar para los habitantes retornados, a partir del significado que toma el desastre para ellos; de la descripción y valoración ciudadana del tipo de política pública aplicada para enfrentar el riesgo, en términos de los impactos que ha generado en los habitantes de la zona; y la identificación y análisis de las acciones colectivas de reconstrucción llevadas a cabo por los ciudadanos que retornaron a Chaitén.

\section{Metodología}

Para producir la información necesaria que permitiese llevar a cabo estos análisis se utilizaron estrategias cualitativas; específicamente, se trabajó con una muestra de habitantes que han retornado a Chaitén, a través de dos técnicas de producción de información: entrevistas en profundidad

22 Op. cit. 
(individuales y grupales) y talleres de discusión. Se decide trabajar sólo con habitantes que han retornado a la ciudad, dado que son quienes han generado acciones concretas respecto de la transformación de su entorno, y quienes se encuentran directamente en la lucha por mejorar sus condiciones actuales de vida, a través de acciones políticas que aparecen como interesantes de analizar. Cabe señalar que la muestra es de tipo estructural, esto es, los sujetos en cuestión muestran unas ciertas posiciones discursivas diferenciadas en la estructura social23; por lo tanto, la representatividad de la muestra no habla de una representación proporcional, sino de una representación de posiciones; se buscan, de este modo, tipos discursivos, los cuales se elaboran a partir de atributos de identidad, esto es, características que poseen los sujetos o colectivos de informantes. Para este caso, se utilizaron como criterios de inclusión los siguientes: ser ciudadano de Chaitén, haber vivido la experiencia del desastre natural y haber retornado a la ciudad. Como criterios a variar, se trabajó con el rol en la estructura de participación social de los

23 Mejía, 2000. habitantes, así, se varió entre sujetos que participaban formalmente en organizaciones sociales y entre aquellos que no; y entre sujetos que cumplían un rol como funcionarios públicos del gobierno local, y aquellos que no ${ }^{24}$. De este modo, la muestra estuvo compuesta por 17 personas, las cuales, en relación a las técnicas de producción de información, se distribuyeron de la siguiente manera: Se entrevistó individualmente a 6 personas: 3 sujetos que participan formalmente de organizaciones sociales, como dirigentes; y 3 representantes del gobierno local (Alcalde, encargado de la Dirección de Desarrollo Social, y Director de Obras de la Municipalidad). Por otra parte, se entrevistó grupalmente a 6 sujetos que no participan de organizaciones formales (3 del sector norte de Chaitén y tres del sector sur). En cuanto a los talleres de discusión, se realizó sólo uno y consistió en la creación deuna cartografía participativa con 5 personas en calidad de informantes claves (un dirigente de una agrupación de desplazados, una funcionaria de la I. Municipalidad de Chaitén y una familia de comerciantes que formó parte del grupo que inició

24 Este último criterio se considera relevante, pues, por una parte, interesa conocer la perspectiva de funcionarios del Gobierno Local, ya que son las autoridades presentes notoriamente en el proceso de retorno y reconstrucción de la ciudad; y, por otra, porque quienes ejercen estos roles públicos son ciudadanos de Chaitén, en su mayoría nacidos y criados en la zona, considerados "un vecino más" por los otros habitantes, y que si bien ejercen un cargo político, pertenecen al colectivo "habitantes retornados a Chaitén".

revista invi №80 / Mayo 2014 / Volume No 29: 143-168 149 
el proceso de retorno a la ciudad). El principal objetivo que orientó el taller, fue la espacialización colectiva de las problemáticas territoriales identificadas por los participantes y la identificación de hitos territoriales previos y posteriores al desastre, con el fin de evidenciar transformaciones en la forma de habitar el territorio.

Es importante mencionar que toda la muestra pertenece al área urbana de la comuna; por lo tanto, la información obtenida rescata el discurso respecto a las principales percepciones, conflictos y acciones que tienen lugar en este sector, el cual, si bien no fue el único impactado por el desastre, ha sido considerado como un punto de partida necesario para abordar las problemáticas socio-territoriales visibilizadas luego de la erupción y tras el retorno.

Posteriormente, luego de transcribir las entrevistas y el taller de discusión, la información producida se analizó con herramientas de la teoría fundada, a nivel de codificación abierta y relacional, para lo cual se utilizó el software ATLAS.ti. Lo anterior permitió generar análisis descriptivos y relacionales de los textos producidos, organizando la información a través de la elaboración y la reflexión de conceptos y categorías ${ }^{25}$, que permiten identificar y clasificar conceptualmente un conjunto de datos, examinándolos con el fin de definir ejes temáticos que ayuden a clasificar el contenido de

25 Murcia y Jaramillo, 2001. dichas unidades de análisis, para posteriormente relacionar estas categorías entre sí destacando ejes centrales del discurso, enlazando las categorías en cuanto a sus propiedades y dimensiones ${ }^{26}$ para formular explicaciones sobre los fenómenos.

A continuación se presentan dos ejes de análisis, a partir de los cuales se organiza la reflexión en torno a los principales conceptos y categorías emanados de los textos analizados. En primer lugar, se presentan las significaciones que los habitantes que han retornado a Chaitén realizan del desastre y las respectivas etapas de este que ellos identifican, para luego dar cuenta de las representaciones que estos sujetos tienen acerca del Estado en cuanto actor social y su accionar a través de la política pública. La relación entre dichas categorías le otorga un carácter socionatural a los desastres, dejando de lado la visión de estos en cuanto expresión exclusiva de la naturaleza.

A partir del escenario descrito en el primer eje, el segundo se organiza considerando elementos clave para los ciudadanos en la conformación de identidad territorial y se discute el concepto de disputa por el territorio o soberanía territorial; posteriormente, a partir de los elementos señalados, se reflexiona acerca de la emergencia de sujeto político y la configuración de acciones colectivas por parte de los ciudadanos que han retornado a Chaitén. 
Finalmente, se presentan algunas reflexiones que profundizan las temáticas abordadas en el análisis, relevando lo social de los desastres en relación a las tensiones entre el Estado y la ciudadanía que se generan en un territorio determinado al sufrir eventos de esta naturaleza; y discutiendo algunos elementos centrales a considerar en el diseño de políticas públicas de gestión del riesgo ante desastres socionaturales.

\section{Eje 1: De desastres naturales a desastres socionaturales. Representación del Estado en Chaitén y percepciones acerca de la política pública}

\section{SIGNIFICACIÓN DEL DESASTRE}

Una de las categorías que emerge como central en los discursos analizados es la significación del desastre por parte de los habitantes que han retornado a Chaitén; al respecto los/as entrevistados señalan:

"Porque aquí a nosotros no nos hizo daño la naturaleza, el que nos hizo daño fue el Estado chileno, porque no se hubiera desbordado el río, porque ellos viajaban a cada rato al volcán (...) aquí fue el Estado el culpable de lo que sucedió" 27 .

"Eh... bueno, si tú miras el desastre mismo, vas a ver que el desastre fue el... desborde del río Blanco. Ese fue el desastre, ese fue el que causó mayores daños."28

"(...) el desastre, por llamarlo así de alguna forma, comienza eh, creo yo, con... cuando la autoridad se empeña en... en sacar a la gente (...)"29.

A partir de lo anterior es posible observar que la erupción del volcán pasa a segundo plano frente al desborde del río Blanco, evento definido como desastroso en la medida en que se encuentra asociado a una acción inoportuna por parte del Estado; cuyos funcionarios, desconociendo las dinámicas propias del territorio, no logran tomar las

27 Entrevista dirigente social, Presidenta Junta de Vecinos “Chaitén Vive". Entrevista realizada por equipo del Centro de Investigación en Vulnerabilidad y Desastres Socionaturales (CIVDES). Abril 2012.

28 Entrevista dirigente social, Presidente Club Deportivo "Ave Fénix". Entrevista realizada por equipo del Centro de Investigación en Vulnerabilidad y Desastres Socionaturales (CIVDES). Abril 2012.

29 Entrevista dirigente social, Comité de Vivienda Santa Bárbara. Entrevista realizada por equipo del Centro de Investigación en Vulnerabilidad y Desastres Socionaturales (CIVDES). Abril 2012.

revista invi No80 / Mayo 2014 / Volume N² 29: 143-168 151 
decisiones correctas en el momento apropiado; por ejemplo, los habitantes solicitaron el drenaje del río, pues intuían que podría desbordarse; sin embargo, el Estado no acoge esta demanda. De este modo, el momento en que comienza la intervención del Estado sobre el territorio de Chaitén es señalado como el inicio del desastre; esto debido a que la inundación de la ciudad obliga la evacuación y dispersión de la población chaitenina.

En esta línea, es posible también reconocer cómo las etapas del desastre son significadas por quienes lo vivieron. Las etapas identificadas y descritas por los entrevistados, en orden cronológico, corresponden al proceso de evacuación-desplazamiento $\mathrm{y}$, posteriormente, a las etapas de retorno-reconstrucción. A continuación se presentan fragmentos de entrevistas que dan cuenta de las significaciones que les son otorgadas por sus protagonistas:

\section{EVACUACIÓN-DESPLAZAMIENTO}

"Entonces por ahi parte un poco eh, creo yo, el desastre como usted decía. Por el hecho de que se disgrega la población, sin importar, una de las cosas que nos llamó siempre la atención: fue sin importar si el grupo familiar se disgregaba o no. Eso jamás interesó. De hecho, cuando nos sacaban, nos empezaron a sacar de Chaitén, no les importó sacar a la mamá con los hijos, o solamente los hijos. Se permitía en un comienzo que solamente subieran las mujeres, los hombres no podían subir. Entonces yo creo que por ahi parte la tragedia, digamos"30.

“(...) Nosotros siempre en Chiloé hablábamos del exilio, porque en el fondo el desplazamiento fue un exilio interno. Y en realidad a la gente de Chaitén le fue muy difícil poderse ambientar en los lugares, incluso hay gente que se ha quedado y que es gente que nunca se ha acostumbrado en un pueblo (...) Entonces algunos pasaron muy bien en la época de las ayudas, otros tuvieron algunos problemas, especialmente de trabajo, pero la mayor parte no se acostumbra"31.

\section{RETORNO-RECONSTRUCCIÓN:}

"Bueno, yo en principio dije que yo no me iba a ir, yo siempre dije que mi casa yo no la dejaba y fui uno de los primeros que me puse a limpiar mi casa y siempre me decian: ¿qué estás haciendo? Si vamos a tener que irnos de acá. Yo siempre decía: "Ustedes se van. Yo no me voy a ir". Y seguía trabajando y siempre tuve fe. Tuve fe en el de arriba de que teníamos que volver (...) Y seguí, seguí. Después ya al tiempo llegó uno, después al tiempo ya el otro. Y eso le da más fuerzas para seguir trabajando

30 Entrevista dirigente social, Presidente Club Deportivo "Ave Fénix". Entrevista realizada por equipo del Centro de Investigación en Vulnerabilidad y Desastres Socionaturales (CIVDES). Abril 2012.

31 Cartografías participativas con actores clave. Taller realizado por equipo del Centro de Investigación en Vulnerabilidad y Desastres Socionaturales (CIVDES). Abril 2012. 
en tu casa. Y como dije, nosotros estábamos viviendo en Palena y ya llegó el tiempo en que le dije a mi señora que entreguemos el local de arriba, que estábamos arrendando en Palena y yo me vine, y empezamos, empezamos, empezamos y aqui estoy. Y ha vuelto mucha, mucha gente. Y ahora ya estamos... vivos"32.

"(...) ahora se viene la nueva colonización territorial de este cuento y normalmente los que han llegado son los chacanos, los que tienen un compromiso. No cualquier gente vive acá, hay que tener como un temple muy especial para vivir acá, en la colonización nuevamente, no todos son colonos $^{33}$.

Durante la emergencia se obligó a todas las personas a evacuar la ciudad según las directrices que el plan de emergencia nacional señalaba, sin considerar los saberes locales ni la estructura social y familiar de los ciudadanos. Posteriormente, las personas fueron enviadas a comunidades de acogida como Puerto Montt, Castro y Coyhaique, que son ciudades con ritmos de vida y estructuras sociales muy distintas a las existentes en Chaitén (relaciones de familia ampliada, sentido de comunidad, arraigado en el territorio y la relación con la tierra, entre otras ${ }^{34}$ ).

De este modo, la evacuación y posterior desplazamiento, se caracterizan principalmente por los

32 Ibid.

33 Entrevista representante gobierno local, Alcalde de la I. Municipalidad de Chaitén. Entrevista realizada por equipo del Centro de Investigación en Vulnerabilidad y Desastres Socionaturales (CIVDES). Abril 2012.

34

Marchant, 2010. problemas de adaptación que experimenta parte de la población chaitenina en sus lugares de destino; problemas que se encuentran vinculados a los cambios en "el estilo de vida" que trae consigo la ciudad. Al respecto Rojas ${ }^{35}$, a partir de un estudio realizado con comunidades desplazadas por efecto del terremoto y tsunami del año 2010, señala que los desplazados son ubicados en un no lugar: "Un no lugar, no de ellos, no elegido por ellos. A este lugar llegan con lo poco que tienen, con lo que les queda (...) El no lugar representa la no vida, el desarraigo, el des-sentido"36.

Luego, es posible observar que el proceso de retorno y reconstrucción encuentra justificación en la nostalgia por un estilo de vida que no se encuentra en la ciudad y que se reafirma ante el imaginario del "colono", aquellos primeros pobladores que llegaron sin nada y que de todos modos lograron sobrevivir. Lo que tiene relación con lo que sostiene Orella ${ }^{37}$, en cuanto a que los espacios vividos cotidianamente por un grupo social que lo reconoce como tal y se reconoce en pertenencia, forman parte de una extensión territorial apropiada por quienes lo viven, de forma tal que quienes se 
apropian de ellos mantienen la voluntad de permanecer en ellos, aunque se les califique de riesgosos.

En definitiva, para los entrevistados el desastre se asocia a la alteración en sus formas cotidianas de vida a causa de acciones inoportunas por parte del Estado, a nivel de manejo del riesgo; y se encuentra compuesto por etapas que van desde la evacuación de la población hasta una etapa de retorno y reconstrucción. Cada una de estas etapas provoca impactos diferenciados en la población y el territorio y, al mismo tiempo, son cargadas de un sentido particular por sus protagonistas. El proceso de evacuación y desplazamiento es definido como un exilio y; finalmente, el proceso de retorno-reconstrucción es entendido como la "nueva colonización territorial", dando paso a una suerte de lucha, entre el Estado y los ciudadanos retornados, por el repoblamiento y apropiación del territorio.

\section{REPRESENTACIONES DEL ESTADO Y PERCEPCIÓN DE LA POLÍTICA PÚBLICA}

Las significaciones en torno al desastre y sus etapas se encuentran estrechamente vinculadas al carácter que asume el Estado para los ciudadanos retornados en Chaitén; en este sentido, las representaciones que construyen respecto de este actor permiten, por una parte, comprender el carácter social de los desastres, y, por otra, situar las particulares relaciones que se generan entre el Estado y la ciudadanía en situaciones de alta vulnerabilidad social como las que generan y evidencian estos eventos.

\section{EL ACCIONAR DEL ESTADO:}

"Cuando nosotros llegamos a trabajar el... como el 2008, como más o menos en julio entramos nosotros... nos sacaban a cada rato, o sea nosotros no vivíamos en Chaitén, teníamos que vivir en Santa Bárbara o en El Amarillo (...) y no dejaban entrar, parecíamos delincuentes, éramos dueños de nuestras propias casas, pero éramos como unos delincuentes, teníamos que andar con el carnet en la mano pa', entrar (...) y todos los días, a cada rato, nos molestaban los carabineros, los militares (...) Si esta cuestión fue una guerra psicológica del Estado chileno contra nosotros, cuando nosotros nos dimos cuenta de que esto era una guerra psicológica, dijimos: 'nosotros tenemos que ser más fuertes que ellos (...) tenemos que cansarlos a ellos, ellos no nos pueden cansar a nosotros, nosotros los vamos a cansar a ellos"”38.

La cita anterior da cuenta de cómo los ciudadanos que han retornado a Chaitén entienden el accionar del Estado principalmente como una forma de dominación. Así, tras el desastre, el Estado intentaría plasmar un nuevo orden social en la ciudad,

38 Entrevista dirigente social, Presidenta Junta de Vecinos “Chaitén Vive". Entrevista realizada por equipo del Centro de Investigación en Vulnerabilidad y Desastres Socionaturales (CIVDES). Abril 2012. 
regulando los ámbitos de acción de los ciudadanos desde lo que la institucionalidad considera como adecuado para enfrentar el riesgo, como por ejemplo, que no se habite el sector sur de Chaitén, por ser considerado altamente riesgoso; sin mediar, hasta el momento, ningún estudio definitivo al respecto. Todo esto transformó las relaciones del Estado con los ciudadanos en una constante pugna.

\section{EL ESTADO COMO ACTOR SOCIAL:}

"El aparataje administrativo no tiene un modelo de intervención en crisis de emergencia, de emergencia natural en este caso. $O$ al rato lo que siempre se hace es como atajar lo inmediato. Ver a la señora le faltó la frazada, le faltó la canasta, donde la instaló por la noche, pero no hay ninguna proyección a largo plazo. Generalmente el Estado ataca así como la emergencia (...) Pero nunca se dedica a proyectar la intervención en cómo el resto de los equipos se coordinan, para poder focalizar y optimizar los recursos en situaciones de emergencia"39.

"Se dilató mucho el tema del retorno y la reconstrucción que le llamaban, la segunda etapa. Porque el Estado, yo siempre digo que el Estado no está preparado para atender una emergencia. No está preparado para atender el retorno y la reconstrucción"40.

39 Entrevista representante gobierno local, Encargado de Dirección de Desarrollo Social de la I. Municipalidad de Chaitén. Entrevista realizada por equipo del Centro de Investigación en Vulnerabilidad y Desastres Socionaturales (CIVDES). Abril 2012. 40 Op. Cit.
Cabe precisar que cuando se habla del Estado o del gobierno, los habitantes que han retornado a Chaitén se refieren al accionar del gobierno central, es precisamente este el identificado como un ente externo o ajeno al territorio y sus acciones son valoradas por la población, como negativas y negligentes. El gobierno local, para los entrevistados/as, es reconocido como parte del territorio, como un actor social similar, ya que sus representantes forman parte de la cotidianidad de Chaitén, son más cercanos a la población y forman parte de los afectados por el desastre. A este actor se le valora, en general, positivamente.

Puede observarse entonces que, como actor social, el Estado emprende principalmente acciones de nivel "compensatorio" en la zona, proveyendo a sus habitantes de algunas estructuras de oportunidades y servicios básicos, como educación y salud, que permiten el retorno de algunas personas; sin embargo, la calidad de estos servicios es altamente cuestionada por los habitantes y además, las ofertas presentan un carácter temporal, lo que no otorga seguridad a los sujetos en cuanto a la reconstrucción de su ciudad. Junto con esto, se evidencia que la oferta presentada por el aparato estatal para 
el enfrentamiento del riesgo ante el desastre fue altamente precaria.

Los entrevistados sostienen que no existen políticas públicas especializadas para hacer frente a desastres como el que se vivió; de hecho, manifiestan que las acciones que se ejecutaron desde el gobierno central no eran parte de una estrategia a nivel de política pública, más bien se levantaron en la contingencia y duraron sólo el tiempo de la emergencia.

Todas estas acciones se evalúan, por una parte de los entrevistados, como poco transparentes, como un engaño, ya que sostienen que hubo acuerdos y anuncios que posteriormente no se cumplieron:

“(...) como le digo al menos, nosotras vivimos en sector sur, tampoco nosotros sabemos si nos van a arreglar el sector sur, si nos van a dar las casas en arriendo, si nos van a dar la posibilidad de comprar nuestras casas que nosotros vendimos, no se po', se nos mintió mucho igual, porque se engañó también po', porque mucha gente que vendió sus casas, porque ellos dijeron ya eh... usted tiene que vender. O sea algunos dicen, a usted no lo obligaron a vender, pero sí en cierta medida sí obligaron, porque dijeron 'usted tiene que vender y tiene que vender, porque el sector sur no se va a hacer nada, no lo vamos a arreglar, está en zona de peligro, eh... no hay luz, no hay agua no hay nada', entonces... pero usted tiene la posibilidad de que si vende su casa, si el sector sur se arregla, comprar de nuevo su casa... y ahora estamos habitando el sector y no nos han dado la posibilidad de comprar nuestras cosas de nuevo ${ }^{41}$.

Además, la mayor parte de las personas sostiene que estas acciones no se realizaron en los tiempos adecuados, que no hubo información acerca de la oferta pública, que todo el proceso fue lento, que no existió un mecanismo claro de asignación de beneficios como bonos y subsidios, que el apoyo psicosocial fue insuficiente en relación a la cantidad de población afectada y a la magnitud del trauma. Las principales críticas se relacionan con los procesos de retorno y reconstrucción, ya que sostienen que el Estado habría cometido graves errores, principalmente al no cumplir con los proyectos prometidos y al mantener a las personas en un estado de incertidumbre respecto de su futuro en Chaitén. En definitiva, se observa un alto descontento en los habitantes que han retornado a Chaitén respecto del accionar del Estado tanto en relación al momento de la emergencia misma (erupción del volcán y desborde del río), como durante el periodo de retorno, y actualmente, en la reconstrucción de la ciudad.

Finalmente, a modo de síntesis de este eje de análisis, se puede señalar que la relación entre

41 Entrevista grupal chaiteninos. Entrevista realizada por equipo del Centro de Investigación en Vulnerabilidad y Desastres Socionaturales (CIVDES). Abril 2012. 
las categorías expuestas en este apartado permite dar cuenta de un conjunto de elementos que otorgan al desastre natural el carácter de socionatural; esto en la medida en que se observa cómo las amenazas naturales se conjugan tanto con factores geográficos (dónde ocurren físicamente los desastres), como con factores socioeconómicos y políticos de las poblaciones afectadas $^{42}$. Desde esta perspectiva, el problema de los daños se centra en el reconocimiento de quién y qué se encuentra bajo mayor riesgo de sufrir los impactos de los desastres y en la explicación del por qué. Así se redefine el problema y un desastre se considera primordialmente como un asunto de orden social, ya que involucra el desarrollo y la acción humana como el sitio principal del riesgo. En este sentido, se percibe al Estado como el principal responsable del desastre, en la medida en que sus acciones tienen como consecuencia la dispersión territorial de las familias y comunidad en general, la prohibición de retornar al territorio y la incertidumbre constante respecto a su futuro. De este modo, este actor es percibido, por sobre la presencia del volcán, como la principal amenaza en el territorio.

42 Barkoff, 1999

\section{Eje 2: Configuración de la acción colectiva para el enfrentamiento del riesgo: una disputa por el territorio}

\section{IDENTIDAD TERRITORIAL}

Otro de los elementos que surge como relevante para la discusión es el sentido de identidad territorial que puede apreciarse en los habitantes que han retornado a Chaitén, pues determina la especificidad de las relaciones que estos establecen con su territorio y permite comprender las acciones que emprenden en relación al enfrentamiento del riesgo. Desde el discurso de los/las entrevistados y participantes del Taller de Discusión se observan las siguientes representaciones de Chaitén:

"(...) porque Chaitén si bien es un pueblo joven, todo lo que tú quieras, hay mucha gente que tiene sus raíces acá, han vivido acá toda su vida, o sea no conocen otra cosa, ahora han salido a afuera y afuera se han encontrado con un mundo que no es acogedor, no es acogedor como en este pueblo, tú en este pueblo tú dejas las puertas abiertas de tu casa (...) ${ }^{\text {n43 }}$.

43 Entrevista grupal chaiteninos. Entrevista realizada por equipo del Centro de Investigación en Vulnerabilidad y Desastres Socionaturales (CIVDES). Abril 2012.

revista invi No80 / Mayo 2014 / Volume N² 29: 143-168 157 
“(..) Si incluso en Palena no nos adaptábamos que es parecido acá y era por el espacio, por la amplitud, Palena está más encajonado, imaginate lo que estamos hablando"nt.

"Tiene que ver con la calidad de, de vida que tú acá por ejemplo, eh... hoy día, no sé qué hora es, pero tú... o sea, pura paz aquí, no hay un ruido, no hay un semáforo, no hay nada. Tienes certeza, cierta seguridad en el tránsito, cachai, cosas que no están en las ciudades grandes donde están desplazados los de Chaitén. Entonces esas cosas, tienen que ver con, con... calidad de vida en definitiva, qué tipo de educación recibes, qué tipo de salud recibes, probablemente acá tenías una salud restringida, pero tenías una salud cercana"25.

"(...) es que cuando uno habla de libertad, creo yo es que cuando habla de la libertad de disfrutar lo que tiene, el espacio que tiene uno, porque cuando nosotroshablamos y creo interpretar a muchos, cuando hablamos de la libertad de nuestros hijos más que nada, que ellos puedan salir, si quieren salir, a la 1 de la mañana salen y caminan libres, juegan libres por donde quieren. Uno aquí se maneja libremente, por ejemplo yo aquí voy para la villa voy para donde quiera moverme y no tengo que pagar no hay ningún control en la carretera que me esté cobrando por ejemplo ${ }^{246}$.

44 Entrevista representante gobierno local, Alcalde de la I. Municipalidad de Chaitén. Entrevista realizada por equipo del Centro de Investigación en Vulnerabilidad y Desastres Socionaturales (CIVDES). Abril 2012.

45 Entrevista representante gobierno local, Encargado de Dirección de Desarrollo Social de la I. Municipalidad de Chaitén. Entrevista realizada por equipo del Centro de Investigación en Vulnerabilidad y Desastres Socionaturales (CIVDES). Abril 2012.

46 Entrevista dirigente social, Presidente Club Deportivo "Ave Fénix". Entrevista realizada por equipo del Centro de Investigación en Vulnerabilidad y Desastres Socionaturales (CIVDES). Abril 2012.

158 revista invi № 80 / Mayo 2014 / Volumen Nº 29: 143-168
En las citas es posible observar elementos, simbólicos y materiales, que participan en la conformación de identidades territoriales, al respecto Ore$1 l a^{47}$ señala que del lugar se extraen elementos que conforman una identidad individual y colectiva y, al mismo tiempo, estos elementos (que pueden proceder de condiciones materiales, geográficas o históricas), presentan en común la carga de significado asignado por quienes los habitan. Se habla entonces de "espacio vivido", en cuanto extensión territorial apropiada por quienes lo viven y a la cual se atribuye un conjunto de significados, desde donde nace la acción social en la medida en que la memoria territorial moviliza y articula a los actores sociales y sus identidades.

De acuerdo a lo anterior, es posible identificar, en el relato de los entrevistados, formas particulares de relacionarse con su entorno, las que se materializan en formas de habitar el territorio; entendiendo que en el habitar "el ser humano está construyendo su lugar, territorio y sistema de vida para

47 Orella, 2010 
poderse identificar con ellos, sentirlos propios y a la vez pertenecerles, enraizarse ahi y de alguna forma poder proyectarse a partir de ahi ${ }^{48}$ ". De este modo, estas formas de relacionarse y significar el territorio influyen directamente en los procesos de adaptación durante el desplazamiento y en la necesidad, manifestada por los entrevistados, del retorno y reconstrucción.

Finalmente, resulta necesario re-significar el espacio, ya no sólo como escenario en el que se desenvuelven los actores sociales, sino que como elemento central en la constitución de los actores y sus identidades ${ }^{49}$.

\section{DISPUTA POR EL TERRITORIO}

"(...) tiene que ver con un tema de lucha, tiene que ver con un tema de quiénes estuvieron aqui a motor, sin agua, sin luz, cachai. Tiene que ver con un tema de comodidad, de calidad de vida, cachai. Yo creo que por ahí va el tema, el tema de, de, de que no basta decir: "soy chaitenino porque... fui evacuado y volví a Chaitén en 2008." "Soy chaitenino porque ayudé a recuperar el pueblo," tiene que ver un poco con ese discurso, cachai. (...) tiene que ver con un tema de recuperación y con un tema de identidad, cachai, con un tema de lucha"50.

48 Chardon, 2010, p. 22

49 Arteaga, 2003

50 Entrevista representante gobierno local, Encargado de Dirección de Desarrollo Social de la I. Municipalidad de Chaitén. Entrevista realizada por equipo del Centro de Investigación en Vulnerabilidad y Desastres Socionaturales (CIVDES). Abril 2012.
Al respecto, Perló y Moya ${ }^{51}$ ofrecen una perspectiva que permite comprender las relaciones de dominio y control que se han establecido en Chaitén; para los autores, todas las relaciones que se establecen en los territorios entre los distintos actores que participan y que ejercen poder sobre él son altamente complejas, cambiantes, de competencia y de permanente disputa entre actores que mantienen derechos, soberanía, atribuciones y potestad sobre el mismo espacio. Sin embargo, estas relaciones también pueden orientarse a la buena convivencia, negociación y cooperación; configurándose en ciclos que contendrían periodos de estabilidad y convivencia, así como de extremo conflicto, según los factores históricos, jurídicos, políticos y coyunturales del caso. De este modo, las lógicas de funcionamiento de los actores del territorio, principalmente de la ciudadanía, gobierno local y gobierno central, muchas veces son contrapuestas, pues expresan ideologías, proyectos políticos o intereses divergentes entre los poderes, y por ende, se produce el conflicto por la soberanía. Los autores sostienen además que este tipo de relaciones se exacerban y pueden llegar a puntos de inflexión en los casos en que dos o más poderes comparten un territorio relativamente reducido, cuando

51 Perló y Moya, 2003 
se presenta una crisis política a nivel nacional, o cuando se presenta alguna problemática aguda como una situación de ingobernabilidad o una catástrofe natural, como es el caso de Chaitén. Aquí, el conflicto se produce principalmente por el ejercicio de la gobernabilidad y el dominio simbólico, por la soberanía territorial.

En este sentido, Santos plantea que "el espacio geográfico, su materialidad, constituye a la vez una condición y un límite para la acción, una estructura de control así como una invitación a la acción. No es posible hacer nada sin que nuestra acción se relacione con los objetos materiales que nos rodean ${ }^{52 "}$.

Es posible, entonces, identificar relaciones entre sujetos y espacios en el contexto de una disputa por la apropiación material y simbólica del mismo, la lucha con otros actores por el control del territorio y la construcción cotidiana del entorno habitacional y comunitario ${ }^{53}$. Es en esta disputa donde se distingue la emergencia de una acción colectiva orientada principalmenteen la búsqueda del ejercicio de la soberanía territorial.

\section{EMERGENCIA DE LA ACCIÓN COLECTIVA}

"Y ahí qué es lo que pasa, es que se hizo una agrupación por la reconstrucción y el desarrollo (...) fue la

52 Santos en Arteaga, 2003, p. 257.

53 Arteaga, 2003 primera que se hizo para poner en la mesa lo que nos estaba afligiendo en ese momento; o sea, qué políticas públicas podían apoyarnos (...) Nos juntamos en Puerto Montt y estábamos en la plaza y todos nos sentábamos ahí, todos bajábamos para la gobernación que estaba entregando algunas cosas, unas cajas de la ONEMI y frazadas y todo un cuento y entonces de repente 'Don Pedro, usted que ha sido dirigente allá podría participar, encabezar, se podría meter y asi nos juntamos un grupo de personas tanto de Palena como de Futaleufú y de Chaitén (...) Al final armamos esta agrupación e hicimos la tabla de petitorio para conversar con la presidenta, si sabiamos que iba a venir en un momento determinado, y se hizo una reunión con ella (...) y ahí salió todo lo que nosotros pensábamos que podía ser una ayuda para salir de este tema" ${ }^{\prime \prime 4}$.

"La única finalidad nuestra era recuperar espacios públicos perdidos, para volverlos a entregar a la comunidad. Y así recuperamos la escuela, recuperamos la posta, porque donde está funcionando la posta lo recuperamos nosotros. No lo hizo el servicio. Lo hicimos nosotros. Nosotros recuperamos esa casa. Si, nos agrupamos. Grupos de gente que arreglábamos las puertas, las ventanas, le poníamos cortinas, ahi le pusimos cama. Recuperamos unas camillas que estaban en la escuela por allá abajo, las trajimos pa acá. Los medicamentos los comprábamos nosotros. A mí me tocó conseguir medicamentos con una

54 Entrevista representante gobierno local, Alcalde de la I. Municipalidad de Chaitén. Entrevista realizada por equipo del Centro de Investigación en Vulnerabilidad y Desastres Socionaturales (CIVDES). Abril 2012. 
farmacéutica, una amiga en Chiloé... eh... y cosas así po, o sea, la finalidad nuestra fue esa ${ }^{55}$.

De acuerdo a Safa ${ }^{56}$, lo que estaría en juego en conflictos como este "son los derechos de los ciudadanos y sus limites, y la capacidad del Estado y sus obligaciones"; serían entonces conflictos de interés, pero fundamentalmente de gestión del territorio. Respecto de los derechos ciudadanos, organizaciones sociales de distinta índole, en distintos territorios, han buscado solucionar principalmente problemas relacionados con la vivienda y con las condiciones generales de la calidad de vida, permitiendo a su vez la formación de diversas asociaciones vecinales ${ }^{57}$. En el caso de Chaitén, algunos de sus habitantes se asociaron de diversas maneras para hacer frente al desastre y tener una mejor calidad de vida tanto durante el desplazamiento, como al retorno y reconstrucción de su ciudad: agrupaciones de desplazados, comités de viviendas, agrupaciones de reconstrucción, juntas de vecinos post desastre, clubes deportivos, entre otros

En este punto, repensar la noción de actor social y por ende, de acción colectiva, aparece como central en la discusión. El sujeto, desde una postura política, rompe, mediante la igualdad, con las jerarquías

\footnotetext{
55 Entrevista dirigente social, Presidente Club Deportivo "Ave Fénix". Entrevista realizada por equipo del Centro de Investigación en Vulnerabilidad y Desastres Socionaturales (CIVDES). Abril 2012.

56 Safa, 2003, p. 263

57 Safa, 2003; Arzaluz, 2003
}

y distinciones con que opera el reparto de lo sensible. La subjetividad tiene un carácter político, en tanto constituye un proceso histórico mediante el cual los individuos y colectividades, imbricados en relaciones de poder antagónicas, luchan por construir un sujeto cuya identidad sea el fruto de una nueva significación ${ }^{58}$.

Respecto de la forma en que nos vinculamos con nosotros mismos y con nuestros contextos social y natural para dar forma a esta nueva significación identitaria, Cubides ${ }^{59}$ sostiene que es desde una acción más o menos consciente, entendiendo la consciencia a partir de la propuesta de Bauman ${ }^{60}$, quien la conceptualiza como la cualidad de percibir el orden de las cosas; como una entidad artificial, de carácter manifiestamente político y social, que considera el bien común. Las prácticas políticas que los sujetos esgrimen, entonces, podrían ser interpretadas desde una nueva mirada, ya no centrada en las propuestas institucionalizadas de formación y participación ciudadana, sino que desde una comprensión alternativa que estima otras estrategias de convocatoria y vinculación con la gente, más ligadas a sus formas de vida, a sus biografías, aspiraciones y utopías, lo mismo que a

\begin{tabular}{ll}
\hline 58 & Angelcos, 2010 \\
59 & Cubides, 2007 \\
60 & Baumanen Cubides, 2007
\end{tabular}


las nuevas modalidades de organización y agrupamiento de las comunidades ${ }^{61}$.

Desde Touraine ${ }^{62}$ la incapacidad de las normas de interpelar al conjunto de la sociedad impregna en el sujeto un deseo de ser actor, una aspiración cultural, material y política que no se realiza en las instituciones existentes y que busca transformar la sociedad. Y ese deseo aparece, en primer lugar, individualmente, tomando la forma de un sufrimiento, agravio o desgarro de la identidad. Sin embargo, cuando los sujetos logran articularse en torno a proyectos colectivos que desafíen las orientaciones culturales hegemónicas se abre la posibilidad de transformar los valores y significados de las construcciones sociales actuales; como en el caso de Chaitén, donde puede interpretarse que los sujetos que han retornado buscan establecer un mayor control sobre sus vidas, transformando las relaciones de poder que se han establecido en el territorio a partir del desastre vivido, y para ello se han servido de la asociación, al reconocer elementos comunes tanto en sus historias de agravio y desgarro identitario, como en sus representaciones del orden social.

En la misma línea, Arendt ${ }^{63}$ sugiere que la vida política se da siempre en el "entre nos", ya que la presencia de los demás es elemental para configurar

\footnotetext{
61 Cubides, 2007

62 Touraine y Khosrokhavar en Angelcos, 2010

63 Arendt, 2002
}

la acción, por lo que la praxis requiere de la pluralidad de una comunidad que habita un espacio público. Esto no significa que la acción siempre tenga que ser colectiva; sino que la acción vivida y narrada no significa nada si no afecta a alguien, si no transforma las condiciones o las tramas de relación y poder de alguien, si no es apropiada y recordada por una comunidad plural o comunidad pública. Para Alvarado ${ }^{64}$, es sólo en este juego entre lo singular y lo común donde el sujeto es capaz de reconocerse plural en lo común, no se agota en su biografía, sino que se hace sujeto político.

En síntesis, las categorías y conceptos trabajados en este eje analítico permiten apreciar procesos de territorialidad, entendida como "actos dinámicos de apropiación, transformación, culturación y antropomorfización del espacio, volviéndolo así territorio, es decir, un espacio con actores, dueños, defensores y dolientes con sentido de pertenencia hacia esta unidad espacial en la cual se reconocen y son reconocidos porque participan de su construcción y desarrollo ${ }^{65}$ ". De modo que, el hecho de compartir un territorio resulta clave en la construcción, permanencia, reproducción y reconocimiento del grupo, en tanto que establece límites específicos y marca la diferencia entre lo colectivo y los otros. Estas marcas, a su vez, se reflejan en aspectos concretos y

64 Alvarado, Ospina, Botero y Muñoz, 2008

65 Chardon, 2010, p. 26-27 
simbólicos, constituyendo una espacialidad propia de determinada identidad social ${ }^{66}$.

De esta forma, el territorio deja de ser sólo escenario de la acción para convertirse en elemento en disputa y, en este caso en particular, elemento cuya soberanía se disputa contra el Estado. Esta suerte de lucha, da origen al surgimiento de acciones colectivas y la emergencia del sujeto político en cuanto actor social que si bien, en este caso no busca un cambio radical en el orden social, o una transformación del sistema social, sí se moviliza para hacer transformaciones en su entorno más próximo, para ganar mayor control sobre las decisiones que se toman en lo que considera su territorio.

\section{Reflexiones finales}

Como se ha revisado a lo largo de este documento, los fuertes y diversos cambios sociopolíticos que se gestan en las comunidades a partir de la experiencia de enfrentar desastres socionaturales, generan profundos replanteos en las bases del poder político y por ende, en el rol tradicional desempeñado por el Estado respecto de su relación con la ciudadanía. En este sentido, las formas clásicas de intervención estatal mediante políticas públicas en situaciones de desastres encuentran serias dificultades para seguir desenvolviéndose como

66 Arteaga, 2003 lo han hecho; lo que se traduce en la urgencia de aumentar el grado de interacción y participación de diversos actores en el desarrollo de políticas públicas, en el marco de redefiniciones en la relación Estado-Ciudadanía ${ }^{67}$.

Las relaciones entre Estado y ciudadanía que se configuran en este caso de análisis particular, y que son necesarias de considerar a la hora de diseñar políticas públicas para el enfrentamiento del riesgo en contextos determinados de desastres socionaturales, pueden leerse como relaciones de dominio y control del territorio. En este sentido, es posible entonces situar esta relación Estado-Ciudadanía, en el caso de Chaitén, en el contexto de una disputa por la apropiación material y simbólica del mismo, la lucha por el control del territorio y la construcción cotidiana del entorno habitacional y comunitario. Para las personas entrevistadas el desastre socionatural vivido tiene dentro de sus principales responsables al Estado; esto básicamente por las consecuencias que conlleva el accionar improvisado, contradictorio y centralista que ha caracterizado el enfrentamiento de la catástrofe por parte del gobierno central, el que no ha considerado la participación ciudadana como elemento clave en la definición de las acciones a seguir, ni ha dialogado con los saberes locales respecto de las mejores formas de gestionar el territorio y enfrentar el riesgo.

67 Carmona, 2011. 
Es así como un desastre pasa de ser "natural" a tener un carácter "socio-natural"; esto en la medida en que sus principales impactos no obedecen tanto a la acción de la naturaleza como al accionar de políticas públicas que operan en disonancia con las características propias del territorio y la comunidad en cuestión. Al ser el Estado el principal responsable del desastre no es extraño entonces que la ciudadanía lo identifique como "el enemigo" frente al cual se entabla la lucha por el control del territorio en disputa, y ante el cual hay que defenderse a través de acciones de resistencia como protestas, toma de viviendas, enfrentamientos con carabineros, etcétera. Cobra sentido entonces lo señalado por Bengoa ${ }^{68}$, quien vislumbra un futuro colmado de guerras entre "David y Goliat"; en estas guerras las pequeñas comunidades, en un intento por defender su vida, su aire, su entorno, se enfrentan a la lógica del mercado y al accionar del Estado. En esta guerra no se puede delegar la responsabilidad, no hay delegación del poder, en la medida en que los responsables de su futuro son finalmente los propios afectados; son ellos los que deben fijar sus fronteras, los indígenas, los pobladores, los comuneros, la gente común.

Junto a esto, y remitiéndonos a nuestro caso de análisis, los impactos generados a partir de la erupción del volcán Chaitén se materializan hoy en una nueva configuración territorial y, por lo

68 Bengoa, 1996 tanto, en nuevas formas de habitar el espacio. De este modo, las nuevas particularidades del territorio no corresponden tan sólo al escenario en el cual se despliegan los conflictos entre el Estado y la ciudadanía; por el contrario, el espacio se convierte en elemento de disputa entre ambos actores y, al mismo tiempo, los significados que sobre él se despliegan se convierten en elementos constitutivos de una identidad en construcción.

Asimismo, relevar que la construcción de sí mismos que realizan los sujetos al enfrentar crisis como un desastre socionatural evidencian la emergencia de actores políticos y por lo tanto, de nuevas formas de acción y organización para enfrentar el riesgo ${ }^{69}$. Proponemos que la experiencia de enfrentar un desastre socionaturalinfluye en la configuración de sujeto colectivo y político, ésta se anida en los procesos de concientización que tienen lugar en las distintas etapas de un desastre, en el caso de Chaitén, desde el momento de la evacuación hasta el retorno, pero principalmente, en la etapa de desplazamiento, donde los sujetos comienzan a analizar sus posiciones en este "no lugar" y las acciones que el Estado realiza para enfrentar el desastre, tomando conciencia de sus responsabilidades individuales y colectivas en este proceso y del proyecto que quieren construir para dar un nuevo orden a sus vidas y su habitar. 
Finalmente, señalar que en esta línea, el rol del Estado debe relacionarse con la promoción de la participación ciudadana y el resguardo de estas instancias, para asegurar que las políticas públicas diseñadas para el enfrentamiento del riesgo en ocasión de desastres socionaturales sean coherentes con las demandas de la ciudadanía y atingentes a los problemas sociales a los que pretenden dar respuestas. Para ello, sostenemos que es fundamental, por una parte, que el tema de la gestión se riesgo se incorpore de manera transversal a la política pública social. Toda política pública de esta naturaleza que se oriente a los sujetos, debe necesariamente responder a los problemas de pobreza, desigualdad, injusticia, y vulneración de derechos que sustentan tanto las vulnerabilidades de base de las poblaciones siniestradas como aquellas vulnerabilidades que emergen tras los desastres; otorgando espacios a las significaciones del riesgo y del desastre que los propios afectados realizan. De esta manera se puede evitar que la vulnerabilidad subjetiva aumente. Por lo mismo, una política pública social de desastres debiera considerar reformas estructurales en el sistema, no sólo medidas a nivel compensatorio, si realmente se orienta a disminuir el riesgo.

Por otra parte, a partir de los aprendizajes que pueden generarse desde esta experiencia, aparece como relevante que la política pública potencie los niveles locales de gestión, generando además herramientas de prevención y enfrentamiento del riesgo en las comunidades expuestas a desastres socionaturales, en cuanto sujetos que cuentan con capital social para resistir el riesgo. Esto implica, necesariamente, valorar el conocimiento popular de las comunidades para elaborar planes de prevención y protección ante desastres, y junto con el conocimiento técnico y científico que pueden producir los colaboradores públicos y privados del gobierno, desarrollar intervenciones, planes y programas para enfrentar crisis de este tipo, permitiendo principalmente avanzar hacia un trabajo de mayor coordinación de saberes y generando un trabajo mancomunado entre todos los actores sociales que habitan un territorio.

\section{Bibliografía}

ALVARAD0, Sara, OSPINA, Héctor, BOTERO, Patricia y MUÑOZ, Germán. Las tramas de la subjetividad política y los desafíos a la formación ciudadana en jóvenes. [En línea]. Revista Argentina de Sociología. 6(11): 19-43, 2008. ISSN 1669-3248. Disponible en: http://www.scielo.org.ar/scielo.php?script=sci_ arttext\&pid=S1669-32482008000200003\&lng=e s\&nrm=iso

ANGELCOS, Nicolás. La estructuración de la subjetividad popular y el problema de la política. [En línea]. Revista de Psicología. 19(2): 55-78, 2010. ISSN 0719-0581. Disponible en: http://www.revistapsicologia.uchile.cl/index.php/RDP/article/ viewPDFInterstitial/17108/17838 
ARENDT, Hannah. Tiempos presentes. Barcelona, Gedisa. 2002.

ARTEAGA, Catalina. Espacio local, identidades y acción colectiva en la ciudad de México. El caso de Ajusco Medio en la delegación Tlalpan. En: RAMÍREZ KURI, Patricia, coord. Espacio público y reconstrucción de ciudadanía. México, Flacso. 2003. p. 365-392. ISBN 9707013753.

ARZALUZ, Socorro. Ciudadanía y territorio en el Estado de México: la experiencia de los Consejos de Participación Ciudadana en Ecatepec, Tlalnepantla y Nezahualcóyotl, 1997-2000. En: RAMÎREZ KURI, Patricia, coord. Espacio público y reconstrucción de ciudadanía. México, Flacso. 2003. p. 393-434. ISBN 9707013753.p.

ATRIA, Raúl y TAGLE, Matías. Estado y política en Chile: ensayos sobre las bases sociales del desarrollo político chileno. Santiago, Chile, Corporación de Promoción Universitaria. 1991.

BARKOFF, Greg. A history of poverty: Thepolitics of natural disasters in thePhilippines, 1985-95. [En línea]. The Pacific Review. 12(3): 381-420, 1999. ISSN 1470-1332. Disponible en: http://dx.doi. org/10.1080/09512749908719297

BENGOA, José. La comunidad perdida. Ensayos sobre identidad y cultura: lo desafíos de la modernización en Chile. Santiago, Chile, Ediciones Sur. 1996.

CARMONA, Rodrigo. Descentralización y presupuesto participativo en ciudades metropolitanas: alcances y desafíos en un escenario de transformaciones
Estado-Sociedad. En: NARDACCHIONE, Gabriel, comp. Todos juntos. Dispositivos de participación en los gobiernos locales en la Argentina reciente. Buenos Aires, Argentina, Universidad Nacional del General Sarmiento. 2011. ISBN 9875744700.

CHARDON, Anne-Catherine. Reasentar un hábitat vulnerable. Teoría versus praxis. [En línea]. Revista INVI. 25(70): 17-75, noviembre 2010. Disponible en: http://dx.doi.org/10.4067/ S0718-83582010000300002

CHARLÍN, Marcelo. Gobierno, política y políticas públicas. Diálogos de Políticas Públicas. 1(1): 5-11, 2007. ISSN 0718-4581.

CHILE. Ministerio de Bienes Nacionales; Subsecretaria de Bienes Nacionales. Ley 20.385 faculta al fisco para comprar y vender propiedades particulares con ocasión de la erupción del volcán Chaitén. 24 octubre 2009.

CUBIDES, Humberto. Política y subjetividad, experiencia o cuidado de sí y la creación de otros mundos. [En línea]. Revista de Ciencias Humanas. (37): 5567, 2007. ISSN 0121-9677. Disponible en: http:// revistas.utp.edu.co/index.php/chumanas/article/ view/1133

IÑIGO, Isidora y UGARTE, Ana María. Acerca de la experiencia del riesgo social. Aportes para un giro subjetivo en los estudios sobre vulnerabilidad. Revista Polis. Artículo en prensa.

LAHERA, Eugenio. Del dicho al hecho: ¿cómo implementar las políticas? [En línea]. Biblioteca del Congreso Nacional de Chile. 2006. [Fecha 
de consulta: 24 marzo 2012]. Disponible en: http://www.bcn.cl/carpeta_temas/temas_portada.2006-07-25.7747914711/archivos-pdf/politicas_Lahera.pdf

MARCHANT, Juan Paulo. Lágrimas de ceniza: estudio cualitativo sobre la experiencia de los habitantes de Chaitén, asentados en las ciudades de la isla de Chiloé y Puerto Montt. Santiago, ONEMI. 2010. Proyecto de práctica profesional.

MEJÍA, Julio. El muestreo en la investigación cualitativa. [En línea]. Investigaciones Sociales. 4(5): 165-180, 2000. ISSN 1818-4758. Disponible en: http://sisbib.unmsm.edu.pe/bibvirtualdata/publicaciones/inv_sociales/N5_2000/a08.pdf

MURCIA, Napoleón y JARAMILLO, Luis. La complementariedad como posibilidad en la estructuración de diseños de investigación cualitativa. [En línea]. Cinta de Moebio: Revista de Epistemología de Ciencias Sociales. (12), diciembre 2001. ISSN 0717554X. Disponible en: http://www2.facso.uchile. $\mathrm{cl} /$ publicaciones/moebio/12/murcia.htm

NEIRA, Soledad. Gobierno desechó proyecto de relocalización de Chaitén en Santa Bárbara por alto costo: Iniciativa requiere una inversión fiscal de US\$ 300 millones. [En línea].Plataforma Urbana. 2010. Disponible en: http://www.plataformaurbana.cl/archive/2010/05/27/gobierno-desechoproyecto-de-relocalizacion-de-chaiten-en-santabarbara-por-alto-costo-iniciativa-requiere-unainversion-fiscal-de-us-300-millones/

ONEMI. Informe No 243 traslado preventivo de habitantes por erupción volcán Chaitén. (En linea).
REDHUM 2008a. Disponible en: http://www. redhum.org/documento_detail/2181.

- Informe No 245 - 3.900 personas evacuadas erupción volcan Chaitén. (En línea). REDHUM. 2008b. Disponible en: http://redhum.org/ documento_detail/2184.

ORELLA, José Luis. Geohistoria. [En línea]. Lurralde: investigación y espacio. (33): 233-310, 2010. ISSN 1697-3070. [Fecha de consulta: 24 marzo 2012]. Disponible en: http://www.ingeba.org/ lurralde/lurranet/lur33/33orellaateneo/33orela teneo.pdf.

PERLÓ, Manuel y MOYA, Antonio. Dos poderes, un solo territorio: ¿conflicto o cooperación? Un análisis histórico de las relaciones entre los poderes central y local en la ciudad de México de 1325 a 2002. En: RAMÍREZ KURI, Patricia, coord. Espacio público y reconstrucción de ciudadanía. México, Flacso. 2003. p. 173-215. ISBN 9707013753

ROJAS, Jorge. Vulnerabilidad social, neoliberalismo y desastres: sueños y temores de la comunidad desplazada/damnificada por el terremoto/tsunami. [En línea]. Sociedad Hoy. (19): 113-140, 2010. ISSN 0717-3512. Disponible en: http://www.sociedadhoy.cl/sites/default/files/SH19-08.pdf

SAFA, Patricia. La emergencia de ciudadanías y de proyectos de ciudad: los nuevos retos de la planeación urbana. En: RAMÍREZ KURI, Patricia, coord. Espacio público y reconstrucción de ciudadanía. México, Flacso. 2003. p. 253-277. ISBN 9707013753.

revista invi №80 / Mavo 2014 / Volume No 29: 143-168 167 
STRAUSS, Anselm y CORBIN, Juliet. Bases de la investigación cualitativa. Técnicas y procedimientos para desarrollar la teoría fundamentada. Medellín, Universidad de Antioquía. 2002.

VARGAS, Jorge. Políticas públicas para la reducción de la vulnerabilidad frente a los desastres naturales y socionaturales. [En línea]. Santiago, CEPAL. 2002. Serie Medio Ambiente y Desarrollo, N50. ISBN 92-1-322013-8. Disponible en: http://www. eclac.cl/cgi-bin/getProd.asp?xml=/publicaciones/ xml/1/10561/P10561.xml\&xsl=/dmaah/tpl/p9f. xsl\&base=/dmaah/tpl/top-bottom.xsl 